[Agr. Biol. Chem., Vol. 29, No. 4, p. 345 350, 1965]

\title{
The Odor and the Infrared Spectra of Furfuryl Sulfides
}

\author{
By Yataro Obata, Yoshinori Ishikawa and Takeshi Fujimoto* \\ Department of Agricultural Chemistry, Faculty of Agriculture, \\ Hokkaido University Sapporo, Japan. \\ Received October 20, 1964
}

\begin{abstract}
By using furfuryl mercaptan as the starting material, the following sulfides have been prepared: methyl, ethyl, $n$-propyl, isopropyl, $n$-butyl, isobutyl, $n$-amyl, isoamyl, $n$-hexyl, $n$-octyl, n-decyl, allyl, prenyl (3-methyl-2-butenyl), benzyl, propargyl, $\beta$-hydroxyethyl furfuryl sulfides.

Most of these compounds showed grassy or spicy odor which is distinguishable from the roasted-coffee aroma of furfuryl mercaptan. The infrared spectra of furfuryl alcohol, furfuryl mercaptan and the furfuryl sulfides in carbon tetrachloride have also been compared to find the characteristic absorptions for furfuryl sulfides and a medium band has been detected at $1130 \mathrm{~cm}^{-1}$, which could be useful in identifying furfuryl sulfide group.
\end{abstract}

Furfuryl mercaptan has been characterized as an agent of roasted-coffee aroma. ${ }^{1,2)}$ The odor of the mercaptan in high concentration is extremely disagreeable and causes headache. However, when diluted with water or glycerol it shows a strong coffee aroma. The roastedcoffee odor is also recognized in several other vegetable products. Obata et al. ${ }^{3}$ have prepared furfuryl mercaptan from furfuryl chloride and thiourea according to Kirner and Richter, ${ }^{4}$ and suggested the usefulness of the mercaptan as a flavoring agent in tobacco processing. Chierici and Sardella ${ }^{5)}$ have reported difurfuryl mercaptoles prepared by the action of gaseous hydrogen chloride on mixture of furfuryl mercaptan and the corresponding aldehydes or ketones and described that some of these compounds showed a better coffee-flavor than the mercaptan.

* Present address, Sekisui Chemical Co., Ltd.

1) J. Giral and A. Garcia Fernandez, Anales inst. invest. cient. Univ. Nuevo Leon (Monterrey, Mex.) 1, 149 (1944)., C.A. $41,1349 \mathrm{i}$.

2) T. Reichstein and H. Staudinger, Angew.Chem. 62A, $292(1950)$.

3) Y. Obata et al., Reports from the Central Institute of Japan Monopoly Corporation, 54, 78 (1952).

4) W. R. Kirner and G. H. Richter, J. Am. Chem. Soc. 51, 3131 (1929).

5) L. Chierici and M. Sardella, Chimica (Milan) 8, 119 (1853). C.A. 48, $4501 \mathrm{i}$.
On the other hand, the literature contains little information about the odor and biological activities of furfuryl sulfides. Kirner and Richter ${ }^{4}$ reported the first preparation of this series from ethyl bromide and furfuryl mercaptan and described the product, ethyl furfuryl sulfide, as a colorless liquid of pungent odor. Gilman and Hewlett ${ }^{6)}$ prepared $\beta$-chloroethyl and $\gamma$-chloropropyl furfuryl sulfides from furfuryl mercaptan obtained by the reduction of furfuryl disulfide which was prepared from furfuryl aldehyde and sodium hydrosulfide. They showed that the $\beta$-compound had a marked vesicant action which was not so great as that of mustard gas $\left(\mathrm{ClCH}_{2} \mathrm{CH}_{2} \mathrm{SCH}_{2} \mathrm{CH}_{2} \mathrm{Cl}\right)$, whereas the $\gamma$-chlorosulfide produced no skin irritation.

Recently, in a patent ${ }^{7)}$ which was published while this work was in progress, several furfuryl sulfides are prepared as the intermediate of furfuryl sulfoxides, useful as sedatives.

This experiment reported here was undertaken to obtain information about the odor of

6) H. Gilman and A.P. Hewlett, J, Am. Chem. Soc. 52, 2141 (1930).

7) Fujisawa Pharmaceutical Co., Ltd. (by Haruo Saikachi), Japan 16, 267 (1962), Oct. 11, Appl. Oct. 9, 1959.; C.A., 59, $11425 \mathrm{e}$. 
the furfuryl sulfides and to find new flavoring agent for foodstuff. The infrared spectra of furfuryl sulfides, furfuryl mercaptan, and furfuryl alcohol were also studied to provide the basic information for diagnosis of the structure for fulfuryl sulfides.

Although none of furfuryl sulfides has been isolated or detected in nature, the occurrence of several compounds containing furan nucleus suggests a possible presence or formation of furfuryl sulfides.

\section{EXPERIMETAL AND RESULTS}

\section{Furfuryl mercaptan (2-Furanmethanethiol)}

Furfuryl mercaptan was prepared from furfuryl alcohol with thiourea and concentrated hydrochloric acid followed by the decomposition of the intermediate $\mathrm{S}$-2-furfuryl isothiourea and steam distillation as described in Organic Syntheses. ${ }^{87}$

In this method, the use of the very unstable and difficultly available furfuryl halides was avoided and furfuryl mercaptan was obtained in good yield $(56 \sim 57 \%)$ after the distillation under nitrogen at reduced pressure, b.p. $45 \sim$ $47^{\circ} \mathrm{C} / 12 \mathrm{~mm}$.

\section{Furfuryl sulfides}

Slight variation of the precedure of Kirner and Richter ${ }^{4}$ was adequate for the preparation of the entire series reported here. The furfuryl mercaptan (11.4 g, 0.1 mole) was converted into the sulfides by treatment of its sodium derivative with 0.1 mole of alkyl or substituted alkyl halide in methanolic solution $(50 \mathrm{ml})$.

All of the alkyl or substituted alkyl halide except prenyl bromide were commercially available. Prenyl bromide (3-methyl-2-butenyl bromide) was prepared from isoprene and hydrogen bromide ${ }^{9)}$ in $70 \%$ yield, b.p. $50 \sim 51{ }^{\circ} \mathrm{C} /$ $40 \mathrm{~mm}$.

The reaction mixture was refluxed on a water bath for one hour. On cooling the

8) H. Kofod, Organic Syntheses, 35, 66 (1955), John Wiley $\&$ Sons, Inc., New York, N.Y.

9) H. Staudinger et al. Helv. Chim. Acta., 5, 743 (1922). solution was added $80 \mathrm{ml}$ of ethyl ether and separated from the sodium halide by filtration. The methanol-ether solution was evaporated and the residue distilled in a nitrogen atmosphere. The products, colorless or faint yellow liquid of disagreeable odor were collected and analyzed. Yields and properties are summarized in Tables I and II.

Several products turned to brown on standing. Propargyl furfuryl sulfide was most unstable and turned to colored syrup in one week in sealed tude under nitrogen.

\section{Infrared spectra}

Infrared spectra were determined with Hitachi infrared spectrophotometer EPI-S2. Furfuryl mercaptan and furfuryl sulfides were run as $5 \%$ solutions in carbon tetrachloride using $1 \mathrm{~mm}$ cells.

Freshly distilled furfuryl alcohol, b.p. $70^{\circ} \mathrm{C} /$ $11 \mathrm{~mm}$, was used as $2 \%$ solution in the same solvent. Carbon tetrachloride of reagent grade, obtained from the Kanto Chemical Company, was used without further purification. Several of the curves are given in Figs. 1 and 2.

The bands found to be common to all spectra of furfuryl sulfides, furfuryl mercaptan and furfuryl alcohol are as follows: 3150 (weak), ${ }^{10)} 1720$ (weak), 1665 (weak), 1595, ${ }^{11}$ $1505,{ }^{10.11)} \quad 1460,1380,{ }^{11)} \quad 1230 \sim 1250,1155,{ }^{111}$ $1075,{ }^{11)} 1005,{ }^{11} 930,{ }^{11)} 885^{10,11)} \mathrm{cm}^{-1}$

Yamaguchi ${ }^{10)}$ pointed out several chracteristic bands of furans; $3165 \sim 3115 \mathrm{~cm}^{-1}$ due to $\mathrm{C}-\mathrm{H}$ vibrations, $1577 \sim 1558 \mathrm{~cm}^{-1}$ and $1511 \sim$ $1504 \mathrm{~cm}^{-1}$ due to $\mathrm{C}-\mathrm{G}$ vibrations, and also suggested that the characteristic absorption band at $885 \sim 873 \mathrm{~cm}^{-1}$ could be most useful in identifying the furan nucleus. Katritzky and Logowski $i^{11}$ have recorded and discussed the characteristic infrared bands of 2-monosubstituted furans in chloroform solution.

Trotter and Thompson ${ }^{12)}$ have pointed out 10) M. Yamaguchi, Bunseki Kagaku (Japan Analyst), 7, 210 (1958).

11) A.R. Katritzky and J. M. Logowski, J. Chem. Soc. 1959,657 .

12) I. F. Trotter and H. W. Thompson, J. Chem. Soc. 1946, 481 . 
TABLe I. Furfuryl SUlfides, $\underbrace{}_{0}-\mathrm{CH}_{2}-\mathrm{S}-\mathrm{R}$

\begin{tabular}{|c|c|c|c|c|c|c|c|c|}
\hline \multirow{3}{*}{$\mathrm{R}$} & \multirow[b]{2}{*}{$\begin{array}{l}\text { Halide*1 } \\
\text { used }\end{array}$} & \multirow[b]{2}{*}{$\begin{array}{l}\text { B. p. } \\
{ }^{\circ} \mathrm{C} / \mathrm{mm}\end{array}$} & \multirow{2}{*}{$\begin{array}{c}\text { Yield } \\
\%\end{array}$} & \multirow[b]{2}{*}{ Formula } & \multicolumn{4}{|c|}{ Analyses, $\% * 2$} \\
\hline & & & & & \multicolumn{2}{|c|}{ Carbon } & \multicolumn{2}{|c|}{ Hydrogen } \\
\hline & i) & $61 \sim 61 / 12$ & $* 3$ & $\mathrm{C}_{6} \mathrm{H}_{8} \mathrm{OS}$ & $\begin{array}{c}\text { Calcd. } \\
56.25\end{array}$ & $\begin{array}{r}\text { Found } \\
56.22\end{array}$ & $\begin{array}{c}\text { Calcd. } \\
6.25\end{array}$ & $\begin{array}{c}\text { Found. } \\
6.11\end{array}$ \\
\hline Ethyl*a & b) & $77 / 14$ & 47 & $\mathrm{C}_{7} \mathrm{H}_{10} \mathrm{OS}$ & 59.15 & 58.94 & 7.04 & 6.81 \\
\hline$n$-Propyl*5 & b) & $90 \sim 92 / 15$ & 46 & $\mathrm{C}_{8} \mathrm{H}_{12} \mathrm{OS}$ & 61.54 & 61.36 & 7.69 & 7.54 \\
\hline Isopropyl*j & i) & $79 \sim 80 / 12$ & 32 & $\mathrm{C}_{8} \mathrm{H}_{12} \mathrm{OS}$ & 61.54 & 61.77 & 7.69 & 7.53 \\
\hline$n$-Butyl $* 5$ & b) & $102 \sim 103 / 13$ & 60 & $\mathrm{C}_{9} \mathrm{H}_{14} \mathrm{OS}$ & 63.53 & 63.14 & 8.24 & 8.25 \\
\hline Isobutyl & i) & $94 \sim 96 / 16$ & 39 & $\mathrm{C}_{99} \mathrm{H}_{14} \mathrm{OS}$ & 63.53 & 63.18 & 8.24 & 8.05 \\
\hline$n$-Amyl & b) & $117 \sim 120 / 15$ & 56 & $\mathrm{C}_{10} \mathrm{H}_{16} \mathrm{OS}$ & 65.22 & 65.12 & 8.70 & 8.52 \\
\hline Isoamyl $*_{5}$ & b) & $108 \sim 110 / 15$ & 43 & $\mathrm{C}_{10} \mathrm{H}_{16} \mathrm{OS}$ & 65.22 & 65.31 & 8.70 & 8.61 \\
\hline$n$-Hexyl & b) & $130 \sim 131 / 13$ & 43 & $\mathrm{C}_{11} \mathrm{H}_{15} \mathrm{OS}$ & 66.67 & 66.83 & 9.09 & 9.16 \\
\hline$n$-Octyl & c) & $160 / 15$ & 24 & $\mathrm{C}_{13} \mathrm{H}_{22} \mathrm{OS}$ & 69.03 & 69.03 & 9.73 & 9.71 \\
\hline$n$-Decyl & b) & $180 \sim 183 / 13$ & 57 & $\mathrm{C}_{15} \mathrm{H}_{26} \mathrm{OS}$ & 70.87 & 70.89 & 10.24 & 10.23 \\
\hline Benzyl & c) & $160 \sim 162 / 17$ & 53 & $\mathrm{C}_{12} \mathrm{H}_{12} \mathrm{OS}$ & 70.59 & 70.75 & 5.88 & 5.87 \\
\hline Allyl*5 & b) & $87 \sim 88 / 12$ & 49 & $\mathrm{C}_{88} \mathrm{H}_{10} \mathrm{OS}$ & 62.34 & 62.35 & 6.49 & 6.20 \\
\hline Prenyl & b) & $119 \sim 121 / 16$ & 40 & $\mathrm{C}_{10} \mathrm{H}_{14} \mathrm{OS}$ & 65.93 & 66.14 & 7.69 & 7.68 \\
\hline Propargyl & b) & $70 / 12$ & 6 & $\mathrm{C}_{8} \mathrm{H}_{8} \mathrm{OS}$ & 63.16 & 63.22 & 5.26 & 5.15 \\
\hline$\beta$-Hydroxyethyl & c) & $136 \sim 137 / 13$ & 51 & $\mathrm{C}_{7} \mathrm{H}_{10} \mathrm{O}_{2} \mathrm{~S}$ & 53.16 & 53.07 & 6.32 & 6.66 \\
\hline \multicolumn{9}{|c|}{$\begin{array}{l}* 1 \text { i), Iodide; } b \text { ), bromide; and } c \text { ), chloride. } \\
* 2 \text { The analytical data reported in this paper were determined by Mrs. Toyoko Toma in the Depart- } \\
\text { ment of Pharmacology, Hokkaido University. } \\
* 3 \text { Furfuryl methyl sulfide was prepared by Mr. Kenichi Hashizume in his graduation thesis, Depart } \\
\text { ment of Agricultural Chemistry, Hokkaido University, } 1963 \text {. The yield from furfuryl mercaptan and } \\
\text { dimetyl sulfate was } 58 \% \text {. The sulfide was obtained in } 40 \% \text { yield when the reaction mixture of sodium } \\
\text { furfuryl mercaptide and methyl iodide was processed after standing overnight at room terperature without } \\
\text { refuxing. } \\
* 4 \text { Reference } 4 \text {. }\end{array}$} \\
\hline
\end{tabular}

TABLE II. ODOR OF FURFUYL SULFIDES

Furfuryl sulfide

Methyl

Ethyl

$n$-Propyl

Isopropyl

$n$-Butyl

Isobutyl

n-Amyl

Isoamyl

n-Hexyl

n-Octyl

n-Decyl

Benzyl

Allyl

Prenyl

$\beta$-Hydroxyethyl
Pungent, spicy, soysauce-like Slightly pungent, cool, grassy Somewhat grassy, spicy, shightly mint-like

Somewhat sharp, spicy, mint-like Slightly cool, grassy, somewhat fruity

Somewhat cool, spicy

Grassy

Grassy, slighty cool

Slightly cool, fruity (grape) but unpleasant

Something like fresh cut grass

Fatty, mild, slightly peanut-like

Strong, grassy, fresh Matsutake-like

Leek or garlic-like, mild

Grassy, cool, unpleasant

Cool, slightly mint-like that the band in the region of $600 \sim 700 \mathrm{~cm}^{-1}$ is characteristic of the $\mathrm{C}-\mathrm{SH}$ and $\mathrm{C}-\mathrm{S}-\mathrm{C}$ bands. In this study, the frequency associated with the $\mathrm{C}-\mathrm{S}$ band remains approximately constant at $700 \mathrm{~cm}^{-1}$ throughout the series of furfuryl sulfides and furfuryl mercaptan. However, the intensity of this band is comparatively low and the deeply absorbing aromatic band in this area obscures the $\mathrm{C}-\mathrm{S}$ band (cf. Fig. 2, Benzyl furfuryl sulfide).

On the basis of comparative spectral study it can be concluded that medium but sharp band at $1130 \mathrm{~cm}^{-1}$ is associated with the furfuryl sulfide group. The $1130 \mathrm{~cm}^{-1}$ band is not present in the spectrum of furfuryl alcohol nor in that of furfuryl mercaptan. No absorption at $1130 \mathrm{~cm}^{-1}$ also could be detected 

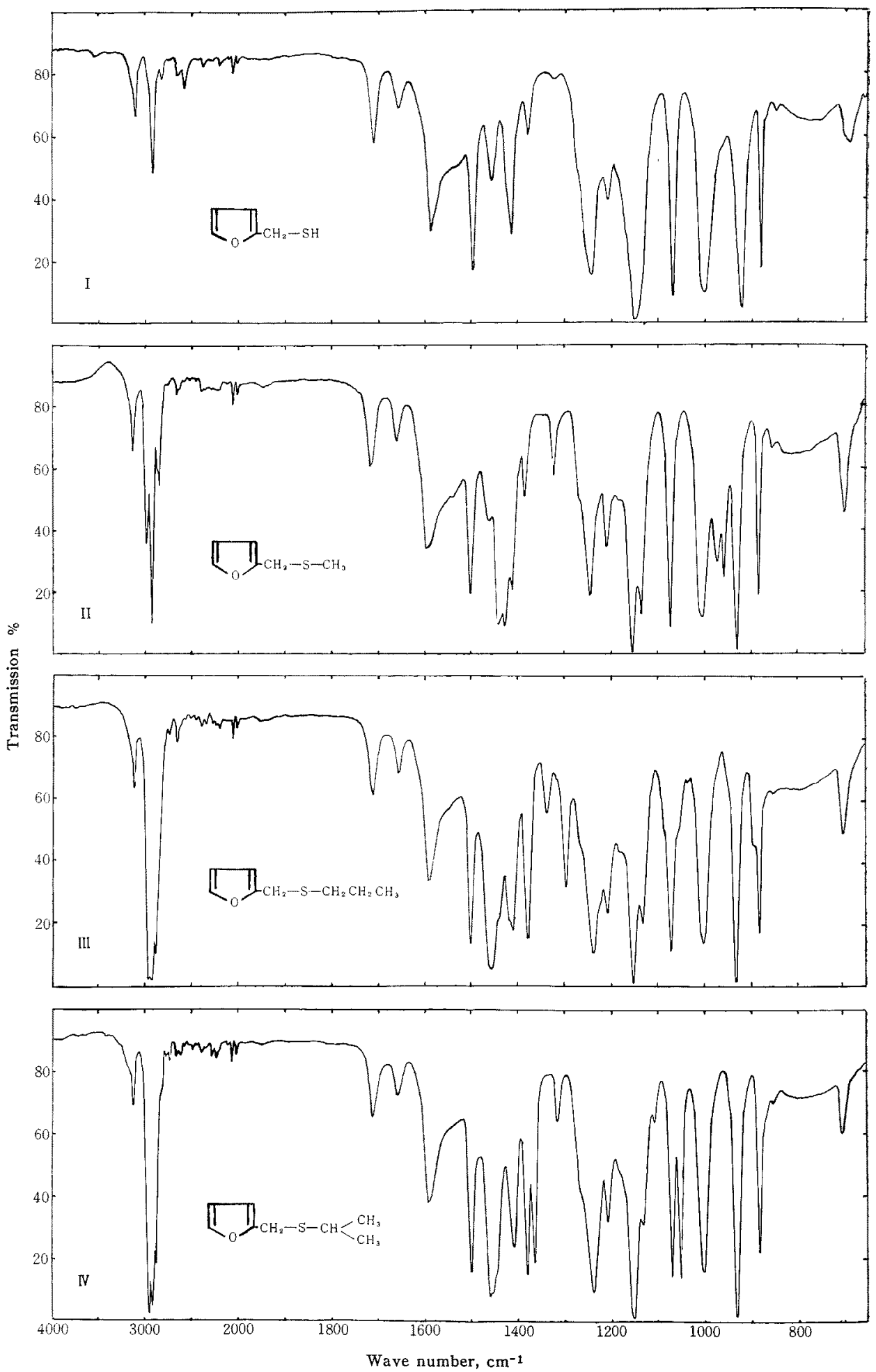

FIG. 1. Infrared Absorption Spectra of Furfuryl Mercaptan (I) and Furfuryl Sulfides. II; Methyl, III; $n$-propyl, IV; Isopropyl 
The Odor and the Infrared Spectra of Furfuryl Sulfides
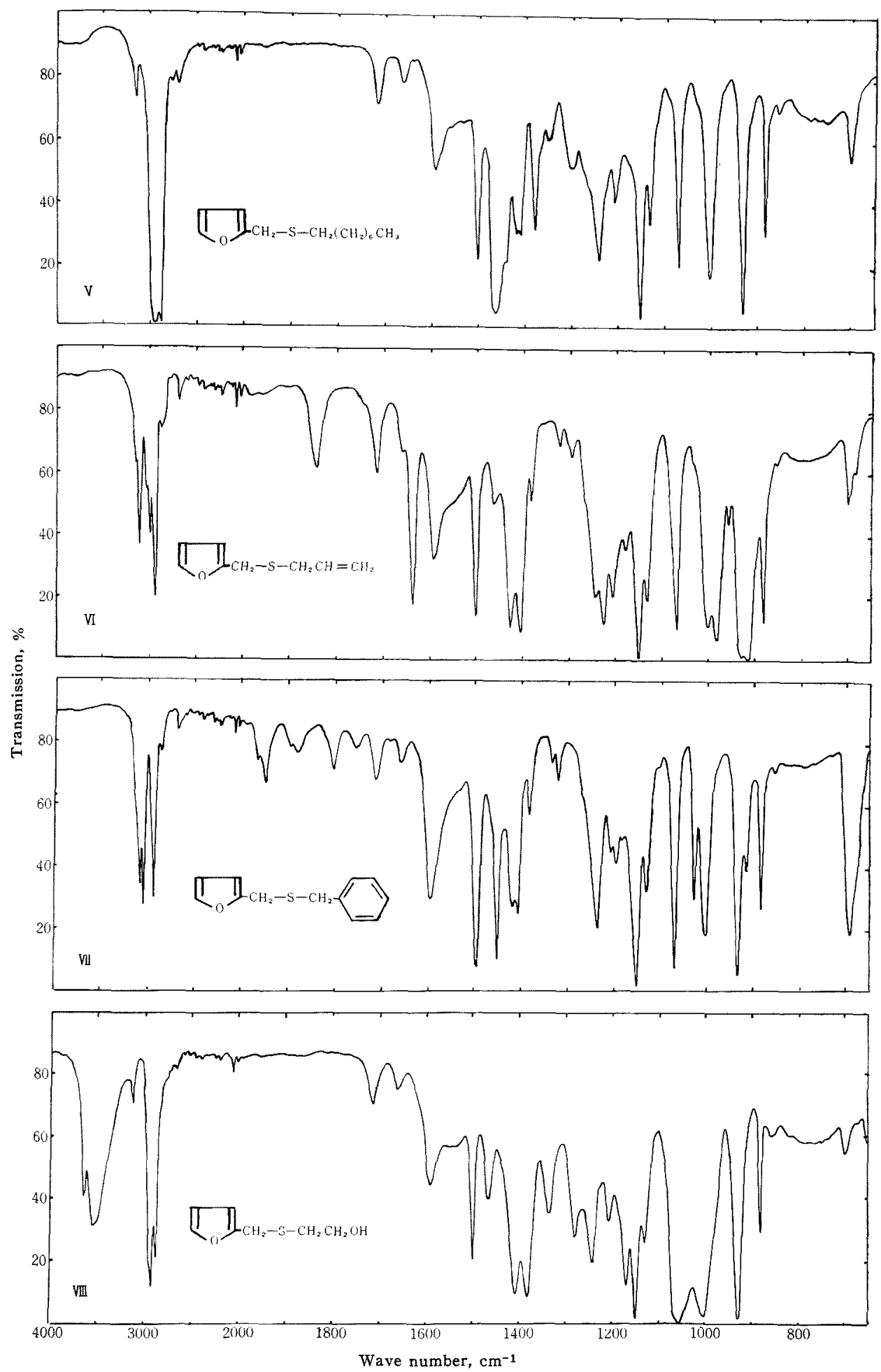

FIG. 2. Infrared Absorption Spectra of Furfuryl Sulfides.

V; $n$-Octyl, VI; Allyl, VII; Benzyl, VIII; B-Hydroxyethyl 
in the following compounds: ${ }^{31}$ Octyl methyl furyl sulfide group for the identification of sulfide, $\beta$-phenyl- $\beta$-hydroxyethyl methyl sul- this structure when it is considered together fide, benzyl methyl sulfide, tetrahydrofurfuryl with the furan bands.

methyl sulfide, linalyl methyl sulfide, linalyl The infrared absorption curves of n-octyl benzyl sulfide, geranyl methyl sulfide and furfuryl sulfide and of $n$-decyl furfuryl sulfide geranyl benzyl sulfide. The $1130 \mathrm{~cm}^{-1}$ band were superimposable except very minor difmay be used as the characteristic band of fur- ference at $1300 \mathrm{~cm}^{-1}$

13) Unpablished data of this laboratory. 